\title{
Interval cancers and bilateral cancers at breast cancer screening
}

Citation for published version (APA):

van Bommel, R. M. G. (2020). Interval cancers and bilateral cancers at breast cancer screening. [Doctoral Thesis, Maastricht University]. Maastricht University. https://doi.org/10.26481/dis.20201203rb

Document status and date:

Published: 01/01/2020

DOI:

10.26481/dis.20201203rb

Document Version:

Publisher's PDF, also known as Version of record

\section{Please check the document version of this publication:}

- A submitted manuscript is the version of the article upon submission and before peer-review. There can be important differences between the submitted version and the official published version of record.

People interested in the research are advised to contact the author for the final version of the publication, or visit the DOI to the publisher's website.

- The final author version and the galley proof are versions of the publication after peer review.

- The final published version features the final layout of the paper including the volume, issue and page numbers.

Link to publication

\footnotetext{
General rights rights.

- You may freely distribute the URL identifying the publication in the public portal. please follow below link for the End User Agreement:

www.umlib.nl/taverne-license

Take down policy

If you believe that this document breaches copyright please contact us at:

repository@maastrichtuniversity.nl

providing details and we will investigate your claim.
}

Copyright and moral rights for the publications made accessible in the public portal are retained by the authors and/or other copyright owners and it is a condition of accessing publications that users recognise and abide by the legal requirements associated with these

- Users may download and print one copy of any publication from the public portal for the purpose of private study or research.

- You may not further distribute the material or use it for any profit-making activity or commercial gain

If the publication is distributed under the terms of Article $25 \mathrm{fa}$ of the Dutch Copyright Act, indicated by the "Taverne" license above, 


\section{Samenvatting}

Borstkanker is wereldwijd een belangrijk gezondheidsprobleem. leder jaar worden ongeveer 2,1 miljoen vrouwen geconfronteerd met de ziekte. In Nederland krijgt één op de acht vrouwen gedurende haar leven de diagnose borstkanker te horen.

Om het risico op overlijden aan borstkanker te verlagen zijn in vrijwel alle landen met een modern gezondheidszorgsysteem screeningsprogramma's geïmplementeerd. In Nederland is tussen 1989 en 1995 een screeningsprogramma geleidelijk over het hele land uitgerold. In dit screeningsprogramma worden alle vrouwen tussen de 50 en 75 jaar om het jaar uitgenodigd voor het vervaardigen van een mammogram. In de afgelopen 30 jaar heeft de screening, samen met de verbeterde therapeutische opties, bijgedragen aan de afname van de sterfte ten gevolge van borstkanker met meer dan $30 \%$.

Van alle gevallen van borstkanker die optreden in de groep vrouwen die deelnemen aan het screeningsprogramma worden de meeste ook gevonden door het programma. Desondanks wordt $20 \%$ van de tumoren in de gescreende groep gevonden in het interval tussen twee screeningsmomenten. Deze tumoren worden intervalcarcinomen genoemd. Intervalcarcinomen zijn over het algemeen groter, groeien sneller en hebben een slechtere prognose dan tumoren gevonden door de borstkankerscreening. De intervalcarcinoomratio (ICR), de verhouding van het aantal intervalcarcinomen ten opzichte van het aantal carcinomen gedetecteerd tijdens de screening, is daarom een belangrijke factor voor het bepalen van de sensitiviteit en kwaliteit van het screeningsprogramma en daarmee ook een belangrijke graadmeter voor de potentie van het screeningsprogramma om de sterfte door borstkanker terug te dringen.

Sinds de introductie van het screeningsprogramma zijn er verschillende technische aanpassingen gedaan in een poging het kankerdetectiecijfer (CDR) te verbeteren en de ICR te laten afnemen. Eén van de recentere veranderingen is de overgang van analoge naar digitale mammografie. In een eerdere studie werd in de eerste ronde van screening met digitale mammografie een toename van de CDR gezien.

Hoofdstuk 1 omvat een algemene introductie en een beschrijving van de doelstellingen van dit proefschrift.

De hoofddoelen van dit proefschrift waren:

a) Het bepalen van CDR in de tweede screeningsronde met digitale mammografie en de latere effecten van de invoering van digitale screening, waaronder de invloed van herhaaldelijke verwijzingen voor eenzelfde afwijking en het vergelijken van tumorkarakteristieken van intervalcarcinomen en carcinomen ontdekt tijdens de screening.

b) De incidentie en karakteristieken van bilaterale, dat wil zeggen beiderzijds optredende, intervalcarcinomen. 
In Hoofdstuk $\mathbf{2}$ analyseerden we de kenmerken van intervalcarcinomen gediagnosticeerd gedurende de overgang van analoge naar digitale screening. Hiervoor verdeelden we de intervalcarcinomen in drie groepen: tumoren gevonden voorafgaand aan de invoering van digitale screening (het laatste screeningsmammogram was analoog en werd voorafgegaan door een eerder analoog mammogram), tumoren gevonden tijdens de overgangsfase (de laatste screening was digitaal en werd voorafgegaan door een analoog mammogram) en tumoren gevonden na de invoering van digitale screening (het laatste screeningsmammogram was digitaal en werd voorafgegaan door een digitaal mammogram). In onze analyse werden gegevens gebruikt van deelnemers aan het bevolkingsonderzoek in de regio BevolkingsOnderzoek Zuid in de periode tussen 2006 en 2014. In deze periode werden 442 intervalcarcinomen gevonden in de onderzochte populatie. De screeningsmammogrammen vervaardigd voorafgaand aan de diagnose van het intervalcarcinoom werden opnieuw beoordeeld door twee ervaren screeningsradiologen om te bepalen of het intervalcarcinoom zichtbaar was op het eerdere screeningsmammogram. Indien het niet zichtbaar was, werd het intervalcarcinoom geclassificeerd als 'occult' en als het wel zichtbaar was als 'gemist' of 'minimale afwijking' waarvan we dit laatste type afwijkingen ook retrospectief niet zouden verwijzen gezien de zeer lage maligniteitskans van dit type afwijkingen. Tussen de eerste en tweede ronde van digitale screening werd er een toename in de proportie van occulte intervalcarcinomen gezien. Deze toename was echter niet meer aanwezig na de tweede digitale screeningsronde. Er werden geen veranderingen in tumorkenmerken en chirurgische behandeling van intervalkanker geconstateerd tijdens de invoering van digitale screening, behoudens een kleiner aandeel carcinomen van het invasief ductale type. Deze bevindingen impliceren dat de initiële daling van de kans op intervalcarcinomen na de invoering van digitale screening later niet persisteert.

In Hoofdstuk 3 werden de kenmerken en prognose van intervalkanker tijdens de overgang van analoge naar digitale screening geanalyseerd. De studie populatie bestond uit 417.746 opeenvolgend verkregen screeningsmammogrammen (302.699 analoog en 115.047 digitaal). Deze werden vervaardigd tussen het jaar 2000 en 2011. Met een follow-up periode van 2 jaar werden data verzameld uit verslagen van beeldvorming, chirurgie en pathologie. We vonden een hoger kankerdetectiecijfer na digitale screening in vergelijking met analoge screening (6,9 versus 5,2 per 1000 gescreende vrouwen, $\mathrm{P}<0,001)$, met een hoger verwijscijfer na digitale screening (31 versus 14 per 1000 gescreende vrouwen, $P<0,001$ ). Hierdoor was de positief voorspellende waarde (PPV) van verwijzing bij digitale screening $22,5 \%$, vergeleken met $37,9 \%$ na analoge screening $(P<0,001)$. In een periode van 11 jaar werden 800 intervalcarcinomen gediagnosticeerd in de screeningspopulatie, waarvan 288 werden ontdekt in het eerste jaar na het laatste screeningsmammogram en 512 in het tweede 
jaar na een negatief beoordeeld screeningsmammogram. 25\% van de intervalcarcinomen bleken retrospectief gemist, hiervan was ongeveer $30 \%$ van de intervalcarcinomen gevonden in het eerste jaar na screening zichtbaar op het screeningsmammogram, en ongeveer $20 \%$ van de intervalcarcinomen ontdekt in het tweede jaar na screening. We vonden geen verschillen in mammografische kenmerken en tumorkenmerken tussen intervalcarcinomen na digitale mammografie of na analoge mammografie. Overlevingsgrafieken toonden een langere overlevingsduur voor patiënten gediagnosticeerd met een intervalcarcinoom na digitale screening dan patiënten gediagnosticeerd met een intervalcarcinoom na analoge screening. Echter, na correctie voor leeftijd, densiteit van het borstklierweefsel, tumorstadium en jaar van detectie in een Cox regressieanalyse, werden geen statistisch significante verschillen meer geconstateerd in overleving $(H R=0,86(0,3-2,6), P=0,3)$. Concluderend laat deze studie zien dat er verschillen zijn in mammografische kenmerken en tumorkenmerken binnen subgroepen van intervalcarcinomen, maar lijkt de overleving op korte termijn vergelijkbaar.

In Hoofdstuk 4 analyseerden we hoe vaak borstkanker gediagnosticeerd werd bij vrouwen die herhaaldelijk verwezen waren voor dezelfde mammografische afwijking. Dit deden we tijdens de invoering van de digitale screening. We keken naar de voorspellende waarde van een positieve screeningsuitslag bij deze vrouwen en specifieke karakteristieken van de tumoren die werden gevonden. Hierbij analyseerden wij de gegevens van vrouwen die gescreend waren tussen het jaar 2000 en 2013. We vonden een toename van het percentage vrouwen dat meermaals werd verwezen voor dezelfde afwijking; dit was $1,2 \%$ in de periode van analoge screening, $2,2 \%$ tijdens de transitiefase, waarin analoge screening geleidelijk werd vervangen door digitale screening, en $2,8 \%$ in de periode na invoering van digitale screening. $\mathrm{Er}$ was een afname in de positief voorspellende waarde van een screeningsuitslag van $35,1 \%$ naar $14,8 \%$ gedurende de transitie van analoge naar digitale screening $(P=0.02)$. Ondanks de vertraging in de diagnose hadden de tumoren, die werden ontdekt bij vrouwen die meermaals werden verwezen, prognostisch gunstigere kenmerken dan intervalcarcinomen; ze waren kleiner en de lymfeklieren waren minder vaak aangetast. Uit deze bevindingen kan worden geconcludeerd dat het ook na de invoering van digitale screening belangrijk is om eerder verwezen afwijkingen te blijven beoordelen en deze vrouwen zo nodig opnieuw te verwijzen.

In Hoofdstuk $\mathbf{5}$ onderzochten we de effecten van verschillende leesstrategieën van de screeningsmammogrammen, geblindeerde en niet-geblindeerde beoordeling door twee screeningsradiologen, op de chirurgische behandeling van tijdens de screening gedetecteerde mammacarcinomen en intervalcarcinomen. In deze studie onderzochten we een opeenvolgende serie van screeningmammogrammen die tussen 2009 en 2011 door twee screeningsradiologen waren beoordeeld. Hiervan waren er 
44.491 blind beoordeeld en 42.996 niet-blind. Borstkanker werd na blinde beoordeling gedetecteerd bij 325 vrouwen en na niet-blinde beoordeling bij 284 vrouwen. In beide groepen onderging de meerderheid een borstsparende operatie $(78,2 \%$ versus $81,7 \% ; \mathrm{P}=0,51)$. Bij ductaal carcinoom in situ gevonden na blinde tweede beoordeling werd na borstsparende operatie een groter resectievolume gevonden dan na niet-blinde tweede beoordeling door de screeningsradioloog $(P=0.005)$. In totaal werden 158 intervalcarcinomen vastgesteld, met vergelijkbaar resectievolumes en een vergelijkbare kans op positieve resectievlakken voor de twee leesstrategieën $(P=0,42$ en $P=0,38)$. Het percentage borstsparend behandelde vrouwen was hoger na niet-blinde beoordeling dan na blinde tweede beoordeling $(P=0,04)$. Deze bevindingen tonen dat de twee vergeleken leesstrategieën (blind versus niet-blind) niet van invloed zijn op de chirurgische behandeling van de bij screening gedetecteerde mammacarcinomen en intervalcarcinomen. Uitzonderingen betroffen een groter resectievolume van de borstsparende ingreep bij tijdens screening gedetecteerd DCIS na blinde beoordeling en een hoger percentage borstsparende chirurgie bij vrouwen met intervalkanker na niet-blinde beoordeling.

Een klein deel van alle intervalcarcinomen is bilateraal. In Hoofdstuk 6 en Hoofdstuk 7 beschreven we de incidentie en tumorkenmerken van bilaterale intervalcarcinomen vergeleken met unilaterale intervalcarcinomen. We includeerden 468.720 screeningsmammogrammen van vrouwen die tweejaarlijkse screening ondergingen tussen januari 2005 en januari 2015. Bij bilaterale borstkanker werd de individuele tumor met het hoogste stadium bij diagnose de indextumor genoemd. Deze indextumoren werden gebruikt voor vergelijking met unilaterale intervalcarcinomen en tumoren gedetecteerd tijdens de screening. In onze studie werden in totaal 753 intervalcarcinomen gedetecteerd, waarvan er 24 bilateraal (3,2\%) waren. Bilaterale intervalcarcinomen waren vaker van het invasief lobulair subtype dan unilaterale intervalcarcinomen $(37,5 \%$ versus $16,1 \%, P=0,01)$ en waren vaker goed gedifferentieerd $(45,8 \%$ versus $27,8 \%, P=0,08)$. Bilaterale intervalcarcinomen waren groter (vaker stadium T2 of hoger bij detectie) vergeleken met bilaterale tumoren gedetecteerd tijdens de screening $(16 / 24(66,7 \%)$ versus $23 / 58(39,7 \%), P=0,03)$. Deze bevinding was te verwachten aangezien unilaterale intervalcarcinomen gemiddeld groter zijn dan unilaterale carcinomen ontdekt bij screening. We concludeerden dat bilaterale intervalcarcinomen een klein, maar niet onbelangrijk deel van alle intervalcarcinomen vormt en dat zij vaker van het lobulair histologische type zijn, met een gunstigere histologische gradering dan unilaterale intervalcarcinomen. 